\title{
Digital Knowledge and Print Preservation: Future Possibilities for Remote Storage
}

\author{
J.P. McCarthy \\ Boole Library, University College Cork, Ireland \\ JP.MCCARTHY@UCC.IE
}

\begin{abstract}
The aim of this paper is to consider some possible directions for the future development of our library cum remote storage facility at University College Cork (UCC) in Ireland and the impact of digital knowledge products on such a future. It is an exercise in crystal ball gazing. The paper attempts to explore an emerging intellectual landscape, one no longer bound by the implications of the physical storage of printed knowledge and it considers what the long term implications might be. It does this by seeking to frame questions about the unknown, about answers as yet to emerge out of what is known through past experience gained in a print technology culture. It questions possible futures for print collections. It questions what are the implications for the future storage of knowledge if we abandon print technology as a storage medium.
\end{abstract}

The paper is in three parts beginning with a stage setting exercise which profiles what currently exists and which gestures towards a vision of what might be. This is followed by a questioning of the challenges and pathways which implementing change might imply. The paper concludes with some reflections. Its core theme is the possibilities remote storage could offer in the transition from print based to digital libraries.

For the purposes of this paper the word digital is loosely defined to mean existence in electronic form and either created in that form or imaged from printed media. Knowledge is defined as information to which some form of intellectual modeling has been applied such as the added value of scholarship or wisdom. By print preservation, I mean preserving book collections not simply because they may carry texts which are not reproduced elsewhere in electronic from. But, because the libraries created from these collections, store and transmit knowledge to us in their own distinctive way and this is something which I believe should be preserved.

Keywords: Storage facility, preservation, digital library, depository, special collections, digital knowledge environment, life cycle, intellectual landscape.

\section{Introduction: Setting the Stage}

\section{The Present Profile}

We are predominantly a print purchasing library acquiring stock at the rate of over 30,000 books alone

Material published as part of these proceedings, either on-line or in print, is copyrighted by Informing Science. Permission to make digital or paper copy of part or all of these works for personal or classroom use is granted without fee provided that the copies are not made or distributed for profit or commercial advantage AND that copies 1) bear this notice in full and 2) give the full citation on the first page. It is permissible to abstract these works so long as credit is given. To copy in all other cases or to republish or to post on a server or to redistribute to lists requires specific permission from the publisher at Publisher@InformingScience.org per annum - quite apart from journal issues and other media, and growing in physical terms at the rate of what must be over 3,000 ft per annum. We occupy a building designed in the early 1970s to hold approximately 600,000 volumes. Our actual print holdings go well beyond this figure. For example we have a remote storage facility located within a 3 mile radius of the campus which cur- 


\section{Digital Knowledge and Print Preservation}

rently contains over 300,000 volumes and which has a projected growth rate of 20,000 items per annum consisting of monographs and journals relegated from the main library and some donations/presentations taken in directly to the Store. In the Boole Library building - our building is named for George Boole inventor of Boolean logic and our first Professor of Mathematics, the print stock profile is predominantly one of books and journals acquired to form a teaching and research resource for the faculties. There are also some groupings of stock which were either acquired because of special attributes or extracted from the main run of stock for similar reasons. This material is described as Special Collections. Each collection has a theme threading it together, giving it integrity of its own. Themes can be subject specific, person related, heritage related. In terms of age, our holdings - our knowledge pile of printed stock, ranges from the most recently acquired 2003 imprints back to our incunabula, with each century in between represented.

As a map of printed knowledge the spread of subject headings within our catalogue shows a widely spread tapestry, thin in places, heavily embroidered in others. This is a map of knowledge set in fixed structures both within texts and by the classification scaffolding we have imposed on it. The map charts an intellectual landscape and its architecture as sketched by a 500 year old print technology. New technology offers the opportunity to change the paradigm. Will any of the old landscape survive? Will print libraries as we know them survive or will they become remotely housed, closed access museological entities - the preserve of heritage custodians? Perhaps we should begin exploring such questions by spec ulating on a vision of the future.

\section{A Vision of a Future Library}

What form might such a vision take? A multimedia subset of the total corpus of knowledge in existence to which we have local access constrained by what we can afford perhaps? Such access to exist only as an entity on the College website through which some remote and some locally stored knowledge artefacts would be accessible along with value added elements to guide, advise, organize, and aid interpretation. Would it be totally a library without walls, without any physical existence in common parlance, perhaps without any human organization to run it?

\section{The Assumptions}

There are some assumptions in such a scenario. Firstly that all print technology will become redundant in favour of digital alternatives and that all of the intellectual product which we currently hold and that which we would like to hold, would be available in digital form either to acquire or to access. Secondly that we would choose to abandon the knowledge stored unwittingly in our print collections i.e. the craft of the book, the typographic knowledge, the casing know ledge, the cultural elements reflected in the manner in which text is structured and stored. Thirdly, that the veils of an intangible, 'invisible web' of knowledge will have been penetrated significantly by the spiders of powerful search engines. Beneath these assumptions is a view that we must move on from a traditional concept of knowledge storage which traditionally we believe has served us well. But, moving to new paradigms creates perspectives perhaps never seen before. So how does the traditional library look from the digital viewpoint? Gordon Springer and Timothy Patrick (Springer, 1995) of the University of Missouri-Columbia make several pertinent observations about the classical or traditional library in this regard:

"One of its shortcomings is that it is designed to store and retrieve documents not information or knowledge."

"That this limits the ability of users to extract information or knowledge in an intelligent way."

"That in a digital library environment it would be a serious injustice to continue to only extract documents" 
In summary they say:

"The digital library brings with it the need to break with the traditions of the classical library. We need to seek out better ways to increase the dimensionality of the information space to provide a wider variety of pathways to the information contained within the space."

The space they appear to refer to is a three dimensional space represented by knowledge / information stored on a library's shelves and in their view accessible only through the pathways provided by a classification scheme and by traditional text structures. So in breaking away from traditional designs in knowledge storage and access, we may in time separate from not only a traditional physical storage of knowledge but also from concepts of knowledge access and use thereby evolving new models in our understanding of the purposes of knowledge and of learning. In such a context perhaps is it only in our background storage facilities, the depositories for less used and less in demand stock, that traditional concepts of knowledge organisation and use will survive? How might future scholars coming from a digital tradition view the now commonplace methods of accessing it? The intellectual content of such a knowledge store may be known to them but would they derive the same degree of meaning from it that we do? Would they find that the interpretation of meaning was restricted by the medium in which the knowledge was stored?

\section{Between the Vision and the Present is a Story Yet to be Told}

Were we asked in the near future to adapt to a campus wide strategy to abandon print based technology totally in favour of digital alternatives how would we go about responding and to what extent would we succeed and over what period of time would we phase the transition from one scenario to another? There are many predictions and forecasts in the literature and it is easy to quote 'ad nauseam'. Perhaps, however, the more creative way to explore such issues is to express them as questions in an attempt to go some way towards visualizing where the bridging concepts between the two may lie : to sketch the possibilities of the strategy by questioning rather than by answering. So what are the questions? They lie within the framework of challenges presented by the impleme ntation of the strategy.

\section{The Challenges of Implementation}

\section{How Would We Go About Responding?}

Perhaps initially only in a very Irish fashion by asking questions about questions.

Here are a few :

- What Budgetary issues will there be?

Initially budget allocations may target the acquisition of new knowledge products either as alternative access resources or as replacements for print resources. There is not much in this to rock the boat. The impact overtime however, perhaps as the acquisition of print knowledge decreases, will possibly affect all aspects of the structure of a budgetary plan. One wonders about the forces which would influence such budgeting, how the elements of the plan would change and how its strategies would become reconfigured? Indeed one wonders about the extent to which such plans would drive us towards a digital future and dictate what it will be?

- What of stock acquisition?

What constraints will there be on purchasing and selecting?

As with journals will we be forced to buy what we want bundled in with what we do not need? It is interesting to watch the impact of a similar issue within the music industry. Will we be able to afford what we want? What opportunities will exist to expand significantly the scope of knowl- 


\section{Digital Knowledge and Print Preservation}

edge already available from our holdings? How much buying of digital texts will be retrospective replacement? How much current, new knowledge? Will the configurations in which we currently acquire knowledge remain with us for the future? How will the design of knowledge products as we know them develop in time? How will multiple access alternatives, text customization, the once-off assemblage of texts on demand, a loss of permanence, a loss of authentication, affect our selecting and purchasing decisions? How will commercial electronic reference services, online reference experts and personalized credit card pay-per-access options affect the picture?

\section{- What of preservation?}

How much investment in the digitization of special and/or locally focused print and manuscript resources should we undertake? Should we become more involved in the capturing of locally produced knowledge and in its dissemination in digital form? How do we define digital storage he re? The creation of intangible facsimiles? The transfer of information / knowledge objects to a more fluid, more manipulable platform?

- What of building use and furnishings?

In a scenario where shelving for bookstock is being dismantled and much free floorspace is becoming available for other uses what strategies for space use will present the mselves? More reader places? But to read what - laptop screens? More PCs?

\section{- But to access what?}

What is already available through a wireless laptop anywhere you may wish to be? Some of the thinking one encounters in the literature at present seems to assume that a digital centre will provide an alternative use for the Library building giving a "bookless" library or a hybrid creature heading in that direction. In such a scenario what happens to the bookstock? Does it get sent to the shredder? Or is it sent to remote storage for a slower demise or perhaps selection for long term preservation in high density warehouse storage according to some set of criteria?

- What of staff?

In such a scenario what happens to all of those staff who operate processes and procedures which are derived from the handling of printed stock. How would a digital library absorb them? What roles could they play in the drama of a digital library? This is a tantalising and a tempting issue, one which could lead us well outside the scope of this paper however. One, where we could sketch much imagery on passing clouds?

- And so, what of stores?

If any of the above questions points to something close to a future reality, what kind of role would there be for our stores? For UCC, like many academic libraries worldwide on the threshold of a digital future, remote storage is an accepted and unavoidable reality for the near future. When we first began to have a remote store for the Boole Library circa 1984, the perception was that of a place for old, low worth, little used stock - an attic, garden shed, garage mentality.

- Why keep this material? Well you never know! Keep it just in case!

As the size of our stock grew and space at the Boole Library became an issue the nature of relegated material changed and as a result the nature of the store's role also changed to being a very active part of library services with a significant requisitions service itself. As our purchasing policy for full-text digital products begins to evolve and as more and more journal titles for example become available online, there is an increasing temptation to relegate print versions of these online titles to store. 
In the grey pool of uncertainty which exists concerning the eventual abandonment of print subscriptions, remote storage seems to offer at least a temporary respite. It affords the library and its clientele a low risk opportunity to test the new paradigm. It releases them from the constraints of a traditional vision allowing for practical experiments in the modelling of new electronic services, in what a digital future might be like without making a full commitment.

\section{How Would We Phase the Transition?}

Perhaps by recognizing that we are dealing with a printed product to which our libraries give a life cycle, moving it from the day it's acquired to some distant day when it may disintegrate with age on the shelf of some remote store. Analysing and quantifying the costs involved in that life cycle may provide the best means of arguing for change to a digital knowledge environment. Do you begin with a major drive to invest in full-text databases that eliminate the need for the back-runs of journals in the store?

In such an environment it is perhaps at the stores that a final decision on the survival of knowledge in print form might be made. It is perhaps there that continued investment in preserving knowledge stored in print technology could be weighed against total transfer to alternative media.

\section{To What Extent Would We Succeed?}

How much of a dream landscape is this future scenario I have given above. How many of the scholarly opinions and ideas in the literature ever really come close to the realities which emerge over time. The gap is perhaps as wide as that between the possible and the probable, between what is actually locally achievable and what might be achieved if only...So how realistic is this digital future? It is probably as realistic, partially as we wish it to be and as we may invest in making it so, partially as much as external forces impose it upon us by reducing our choice options, by demanding newly established technological standards common in society in general, by making it the most responsible budgetary choice.

\section{But What of Digitizing the Stores Themselves?}

What would this mean? A local digitization project? Hardly! A collection development policy which says buy as much electronic access to digital versions of what you hold in store as you can afford and discard the print versio ns as part of this process? Probably! But at what cost? No contingency cover in the case of cancelled subscriptions or a company going out of business? No archival access to the years for which you have already subscribed? No limit fields in search engines which allow such access on an ongoing / ownership basis? At least with a print copy you are left long term with something tangible. And what of dependence on digitized products as a means of setting the cost of access for the future, of sculpting who could access? Are there cost implications in an ongoing migration of data to ever changing storage media? In maintaining the scope of a library's access to knowledge as price structures change? In sustaining continuous investment in forever upgrading software and equipment to access such media? So is it wise to abandon print holdings in favour of electronic access? To cut the tether? The wisdom of heritage and preservation would perhaps say no. Yes, have access/ availability in digital form but keep the print archive safe. But then again the wisdom I'm talking about is the wisdom of a print heritage, a print culture. How might the wisdom of a digital heritage / preservation culture in some future time respond?

\section{What of Print Inundation?}

So far I have dealt with libraries and I have referred to remote storage as though it were some thing which represented the end process in the life cycle of printed knowledge products. As though it would most likely become a repository rather than a depository. The difference is significant. It has been our tradition at UCC to keep everything and in that context we have always had a degree of ambiguity about 


\section{Digital Knowledge and Print Preservation}

which word was most appropriate to describe our storage facility as it grew from something very small in the early 1980s to what it is today. But as we now begin to recognize that significant annual growth at the store will be an important and costly investment for the near future at least, the possibility of alternative methods of storage, of getting maximum value for the investment is becoming an issue. Which raises the question what are the alternatives?

- In a worst case scenario we do nothing and allow the stock to grow rapidly absorbing floor space with fixed shelving units until once again the building is too small and we either move to another building on lease or alternatively we acquire the funding for a custom-built structure.

- Or perhaps we should set about a strategy to gradually introduce mobile shelving until we have absorbed all of the available floor space using this method and thereby increasing the capacity and lengthening the term of occupancy of the building. However in the long term we would still come to a stage where floor space is still an issue and this would again force us to look at moving to either another leased building or towards a custombuilt structure.

- American College libraries faced with similar problem have devised an alternative and this is known as high density storage. The idea here is that you store the stock by size. Stock is then housed on trays in large custom-built warehouses on racking 30 feet in height which is accessed by forklift like vehicles known as cherrypickers. You can see photographs and descriptions of some examples on the Duke University website (see below) and in particular no te the installation at Virginia Tech. These simple form structures are suited to modular development as long as sufficient space is available for expansion in the immediate vicinity of the building.

Underlying current circumstances at UCC there is an assumption that we must continue to keep all we acquire in print, that we do not make policy decisions to weed, to discard, to sell or donate. That we have not decided on a mission, on a future need for this stock. How significant an impact would such a mission statement have on the long term growth of stock at the Store? For us not a major one in the long term. We have looked at our periodicals run $(12,500 \mathrm{ft})$ there and yes, some of it is composed of broken or short runs of titles which could as easily be acquired through interlibrary loans. We do carry duplicate monographs which could be sold. We carry reference works which are out of date and of little interest except perhaps to the historian. We carry many unsorted donations and presentations some of may not bring any real knowledge value to our holdings. We also carry within the covers of these monographs and journals many texts which have never been consulted.

An interesting question to pose in an environment like our store is what percentage of our investment in compiling this knowledge stock over a 150 year period has ever been used or will ever be. Also because of being under-resourced in our retrospective cataloguing activity a very large percentage, perhaps as much as two thirds of the Store's stock, is not registered on the online catalogue and as such is not identifiable as part of the overall collection. So in that case is there much sense in holding onto most of this stock? How expensive is it to store per annum? How much would it cost to catalogue it all. I don't have figures but the costs would be signif icant. So what is my point? It is that a lot of what we currently store may be of little or no value to our scholarly community for the future. Therefore why invest in long term storage? What is the alternative? How would the costs of long term storage and of cataloguing match up with a digital access a lternative to those parts of the holdings identifiable as key research resources? How much should we invest in providing for serendipitous discovery? How much should we invest in preserving collections we regard as special? Such questions require an enlightened collections development policy! 


\section{Keeping Special Print Collections}

When we venture from discussions on the future of main library collections to considering Special Collections we shift from a discussion about the transmission of knowledge content to one concerned with the preservation of the context of that content.

Were a national depository for this part of our national heritage in existence would one also see Special Collections stored there? Perhaps not. Special collections in many ways like museum collections represent far more than the content of the texts of which they are composed. As assemblages these collections possess an integrity whichis in itself a cultural/heritage entity. They can represent a local sense of prestige, of scholarly enrichment, of uniqueness so very important to the identities of individual academic institutions. Therefore local preservation of Special Collections is a very different issue from that of the more general collections of which the Library and its store are composed. One wonders what definitions of 'special digital collections' will emerge in times to come. Will the messages embedded in the collecting process be the same as those for print collections? But to continue with the subject of main collections....

\section{Main Collections - The Digital option}

The first question one is tempted to ask is whether or not there is one as yet, at least of significant proportions to make this alternative a viable option. It is true that services like JSTOR, Project Muse, ECO etc are making significant in-roads in offering electronic access to the corpus of established journal titles. Indeed according to Nisonger (Nisonger, 2000, 641) Ann Okerson forecasts that "between 2000 and 2005 all significant STM journals will be on the WEB, indexing and abstracting will serve as gateways to journal content, electronic books will sweep onto the WWW, archiving solutions will emerge and consortia will grow in power

So were we to try to compare, regardless of cost issues, digital with print alternatives, what de gree of coverage is now available and at what pace is it developing and what is its scope? When should we expect to see a significant amo unt of what we have in print storage available in e-form? Many forecasts and predictions can be found in that the issue of the journal Library Trends quoted above entitled Collection Development in an Electronic Environment. Cutting the tether edited by Nisonger (Nisonger, 2000).

If we reach a stage where abandoning our store holdings, already weeded, is a realistic option, will we take it and at what risk? What will we loose in abandoning our paper landscape of knowledge. Will all the map's routeways, all their twists and turns vanish? Will all that is known be digitally knowable with little or nothing in the way of discovery and exploration? With no arduous routes to scholarly pinnacles ...all bulldozed away by the power of search engines?

\section{National Issue}

But then again, even if UCC were to abandon its print holdings at some future point in time does this imply that such products would be destroyed, that nationally all stores and printed products would be abandoned?

I do not have information regarding other National University of Ireland (NUI) Colleges but I wonder about the extent to which they have similar concerns about the long term storage of print stock and about digital alternatives. Is there a case for saying that in the Colleges of the NUI one could find many copies of the same monographs and serials, many of which are hardly ever consulted if at all. If this is the case what is the logic in long term preservation for all of these. Would it be more cost effective for all involved to have a national depository strategy, a national bibliographic depository which would take responsibility for the long term preservation of our printed knowledge resources and which would take 


\section{Digital Knowledge and Print Preservation}

responsibility for ensuring that access is always available to the knowledge stored in this archive? Who would take responsibility for such a depository? A consortium perhaps, one also charged with consortium deals for electronic products perhaps? One which would concern itself with archiving issues for eproducts and with long term strategies for the migration of digitally stored knowledge to new or alternative storage products? Should such a depository become the advisory centre for a national strategy on the transition from a print to a digital scholarly culture? Is it realistic to ask individual colleges to find independent answers to such questions?

In the creation of such a depository one of the biggest questions would perhaps related to the reaction of scholars to seeing stock which has been locally based and within the immediate control of their own institutions moved elsewhere. What arguments could the academic library community make? E-forms of some products are available campus wide and indeed from where ever you may wish to access them.

Others can be faxed to you, borrowed through interlibrary loans. You can use the library building as a centre for these forms of document delivery. Temporary deliveries and storage of stock can be made to the library to facilitate browsing. This suggests that the circulation of printed stock could still be a major drain on resources. Perhaps the word library is no longer used in favour of the term Learning Resource Centre? A clearing house for knowledge/information interchange, for brokerage and content marketing? Would a residual social memory of the word library relate only to the store?

To quote from a document submitted to the Andrew W. Mellon Foundation by the Milton S. Eisenhower Library of The Johns Hopkins University (1998) a method for "providing real-time browsability of library collections stored at off-campus storage facilities is described. Known as CAPM(Comprehensive Access to Print Materials), the project will result in a national model for library service and access to resources, providing patrons with new electronic capabilities to access, browse and electronically capture information through a cost-saving process that will enhance library service while helping universities control the rising cost of higher education. CAPM addresses Library patrons' primary criticism of book storage facilities i.e. being separated from library materials". The proposal involves The Johns Hopkins Whiting School of Engineering working with IBM, Ameritech and Minolta to develop the system. It is proposed that the system using robotics, automated systems and high speed telecommunications would perform as follows:

"A patron would use the Library's web-based catalogue to identify an off-site stored item. CAPM would transmit a request to retrieve and bring it to a scanning station. Scanning would be done by robotic systems. The pages are scanned, converted to OCR software and indexed. Digital images of the pages are sent across the NET to the patron's browser. Patrons can then request delivery of the physical item or its return to the store's shelves".

One wonders about what subsequent opportunities these scanned documents might offer. An interesting statement made in support of developing this technology and thereby enhancing the future role and importance of storage facilities is "The cost of building and operating the no-frills warehouse is as little as one fifteenth that of a traditional library even considering the expense of delivering materials to campus". So, is there a plausible model in this technology to support a collaborative storage arrangement between Irish academic libraries? Perhaps it is through such an arrangement that the most workable and most cost effective solutions will emerge? As consortium arrangements for purchasing digital know edge products become commonplace, are not similar arrangements to deal with the future of printed knowledge products a reasonable path to follow? 


\section{Conclusion: Reflections}

\section{So Why Choose to Meet the Challenge of a Digital Future?}

Quoting a 1997 inauguraladdress by Dr. William Brody, President of Johns Hopkins Unive rsity the CAPM proposal gives one university's reasoning on why it should invest in alternatives to print libraries.

"In the past libraries have assembled collections of scholarly material-journals, books and manuscripts - and made them available on a 'just in case' basis. Materials filling our library at Hopkins are duplicated in thousands of other libraries, just in case a student or faculty member needs immediate access to the material. Today, few libraries can afford to maintain such collections. So librarians on the cusp of change are looking at 'just-in-time' libraries. These are facilities that will provide access to materials when you need them using electronic access or express delivery. They will not necessarily be required to maintain that information in their own physical collection. Such virtual libraries are technically possible to introduce today... One of my goals is to see this university take up the challenge of redesigning and implementing the library of the future. Financial pressures alone may make this effort a matter of necessity in the near future. This is just one aspect of the physical changes brought about by the information revolution".

Seen in this way, the option of remote storage is significant. But what happens then? When say these new concepts of 'library' service become established? If the digital becomes the norm? What happens to the stores long term? Will they be seen as having any relevance in the role of such future libraries? If not then what will be their value, their purpose in continuing to exist? Perhaps that depends on how passive stores are in shaping such change. Seen as facilitators and perhaps as an instrument for shaping a digital future, remote storage with its developing philosophies and technologies, may as yet offer the safest guide-rails as we cross into an uncertain future. Indeed perhaps it is only at the end of such a crossing that we may finally rationalize their value.

\section{The Future as a Foreign Country?}

We cannot as yet envisage a digital library future in terms of all its implications for the traditional custodianship of printed knowledge. Will it happen? Yes it probably will overtake us whether we wish it to or not regardless of how we plan for it. What will we be left with as the dust settles? Forgotten colections of decaying print stock in remote intellectual wastelands? What migrations will the cultural memory now stored in print take in the centuries to come as newer and newer forms of storage material come into existence? Is there is danger of losing the intellectual wealth of western civilization as we know it because of this? Is the need to preserve this wealth solely the perception of a civilization? Is it merely another form of coinage in such a civilization? What archaeologists will whisper its story? Who can tell? Perhaps in spite of our futuristic predictions and forecasts we know as little of the future as we do of the past. To quote the title of David Lowenthal's famous book The past is a foreign country. And in response the truism has been said... we cannot live there. Indeed can we not also say the same of the future?

\section{Is There a Future to be Avoided?}

One imaginary time traveller who attempted to explore that foreign country of the future recalled to his friends his observations on some monumental remnants of an 'intellectual age' as follows:

"I went out of that gallery and into another and still larger one, which at the first glance reminded me of a military chapel hung with tattered flags. The brown and charred rags that hung 
Digital Knowledge and Print Preservation

from the sides of it, I presently recognized as the decaying vestiges of books. They had long since dropped to pieces, and every semblance of print had left them. But here and there were warped boards and cracked metallic clasps that told the tale well enough. Had I been a literary man I might, perhaps, have moralized upon the futility of all ambition. But as it was, the thing that struck me with keenest force was the enormous waste of labour to which this sombre wilderness of rotting paper testified. At the time I will confess that I thought chiefly of the PHILOSOPHICAL TRANSACTIONS and my own seventeen papers upon physical optics”. (Wells, 1895)

\section{References}

Duke University Libraries. Library Services Centre. Other Remote Shelving / Storage facilities www.lib.duke.edu/lsc/othersites.htm

Johns Hopkins University (1998). A proposal for Comprehensive Access to Off-site Library Print materials submitted to the Andrew Mellon Foundation by The Milton S. Eisenhower Library, May 11. dkc.mse.jhu.edu/CAPM/proposal.html

Lowenthal, David. (1985). The past is a foreign country. New York: Cambridge University Press.

Nisonger, Thomas E. (2000). Collection Development in an Electronic Environment. (Issue title). Library Trends vol.48 (4).

Springer, Gordon K. and Patrick, Timothy B. (1995). Translating Data to Knowledge in Digital Libraries. www.csdl.tamu.edu/DL94/position/springer.html

Wells, H.G. (1895). The time machine: an invention. London: Heinemann

\section{Biography}

James P. McCarthy is a librarian at the Boole Library, University College Cork (UCC), Ireland. Prior to joining the Library profession in 1978 he graduated with a Master's degree in Archaeology from UCC and subsequently undertook his professional education at University College Dublin. He also holds a Diploma in Computer Science from UCC. He has had a variety of roles during 25 years of Librarianship in areas such as Rare Books and Manuscripts, Archives, Systems, Cataloguing, Remote Storage Project Management and Arts Librarian. He has published a few articles, including two on library history one of which won the 1996 Library Association Library History Award. He also has a strong interest in poetry. 